\title{
AVALIAÇÃO DA INCIDENCIA DE PARASITOS CUTÂNEOS EM PEIXES COLETADOS EM GARÇA-SP
}

\section{PARASITES OF INCIDENCE EVALUATION OF SKIN IN FISH COLLECTED IN GARÇA-SP}

\author{
T. M. LIMA ${ }^{1}$, T. ROSENDO ${ }^{1}$, L. A. PIRES ${ }^{1}$, A. M. ANTONUCCI ${ }^{2}$
}

\begin{abstract}
RESUMO
A aquicultura é definida como a criação de organismos aquáticos. Atualmente, é uma atividade que vem se desenvolvendo, a cada ano, por ser uma alternativa de produção de alimentos, além das finalidades esportivas e de ornamentação. Entretanto, alguns parasitos que se alojam no tecido cutâneo do hospedeiro podem prejudicar o desempenho zootécnico do peixe bem como sua atratividade, podendo ocorrer alteração de coloração, inflamação e até escoriações no animal. Os protozoários ectoparasitos podem causar doenças quando condições nutricionais, limnológicas e zootécnicas da criação desfavorecem o equilíbrio provocando estresse aos peixes. Devido a isso, estudos sobre parasitofauna de peixes tornam-se importantes. O estudo realizado na Faculdade de Ensino Superior e Formação Integral FAEF analisou amostras de raspado cutâneo de 30 espécimes. Foram utilizados sete peixes de cada espécies sendo elas: Poecilia sphenops Valenciennes, 1846, Hyphessobrycon eques (Steindachne, 1882), Astyanas spp (Linnaeus, 1758), Satanoperca pappaterra (Heckel, 1840) e dois Leporinus friderici (Block, 1794) coletados em loja de aquarismo e as duas últimas espécies em ambiente natural no município de Garça SP. Os peixes de cada espécie foram submetidos a raspagens da superfície corpórea, com exceção da cabeça, no sentido crânio-caudal e de ambos os lados do corpo. O material coletado foi depositado em lâmina fosca sob lamínula e analisado em microscópio óptico em objetivas de 10 e 40x em sentido da direita para a esquerda em zigue-zague. Dos 30 espécimes analisados, foram encontrados dois Epistylis sp em um peixe Poecilia sphenops, e um ácaro em um espécime de Satanoperca pappaterra (Heckel, 1840). Mediante dados obtidos através desde estudo, pode-se concluir que os níveis de infestação por ectoparasitos dos peixes coletados no município de Garça são baixos, indicando boa qualidade limnológica da água e sanitária dos peixes.
\end{abstract}

PALAVRAS-CHAVE: PROTOZOÁRIOS. ECTOPARASITOS. RASPADO CUTÂNEO. Epistylis SP.

AGRADECIMENTO: FAEF - Garça-SP

ÁREA TEMÁTICA: Doenças Parasitárias 